\title{
The theory of Realistic Mathematics Education as a theoretical framework for teaching low attainers in mathematics
}

\author{
Hayley Barnes \\ University of Pretoria \\ Email: hayley.barnes@up.ac.za
}

\begin{abstract}
This article recounts the process embarked on and reasons for selecting the theory of Realistic Mathematics Education (RME) as the theoretical framework in a study carried out with low attaining learners. In the study an intervention for low attaining grade 8 mathematics learners was implemented in an attempt to improve the understanding of the participants with regard to place value, fractions and decimals, and to identify characteristics of this type of intervention and potential design principles that could be applied in similar interventions. In this article, the theoretical framework for the intervention is discussed and theoretical (rather than empirical) reasons for selecting the theory of Realistic Mathematics Education (RME) for use with low attainers are put forward. From a literature review that looked at the teaching and learning of mathematics to learners who fall into the category of performing below the required standard, five common aspects emerged. Once these aspects had been identified, a theory in mathematics education was sought that encompassed these five aspects. The theory of RME was subsequently selected as the theoretical framework to drive the design and implementation of the intervention and is being suggested as a possible way forward for working with low attaining learners.
\end{abstract}

\section{Low attainers}

Many terms or descriptions are used in the literature to refer to learners in this category. These include terms such as: remedial, disadvantaged, special needs, under-achievers, slow-learners and low achievers (e.g. Denvir, Stolz \& Brown, 1982; Haylock, 1991; Swanson, Hoskyn \& Lee, 1999; Kroesbergen \& Van Luit, 2003), which are used in schools to refer to children with undefined problems. For this article, the term low attainer has been chosen to refer to learners who do not meet the required standard of mathematics performance as set out by the school. This implies that the observable performance of the learners is described, without implying a cause (Denvir et al., 1982).

\section{Teaching and learning mathematics (with specific reference to low attainers)}

From a critical review of the literature on mathematics interventions and programmes for learners with mathematical difficulties (e.g., Baroody \& Hume, 1991; Dockrell \& McShane, 1992; Mercer \& Miller, 1992;), learning disabilities (e.g., Cawley \& Parmar, 1992; Swanson, et al., 1999; Dunlap \& Thompson, 2001; Geary \& Hoard, 2001), Special Educational Needs (SEN) (e.g., Daniels \& Anghileri, 1995; Kroesbergen \& Van Luit, 2003; Magne, 2003) and low attainers (e.g., Hart, 1981; Denvir et al., 1982; Trickett \& Sulke, 1988; Haylock, 1991), there appears to be considerable evidence that arithmetic computation and basic mathematics skills are the dominant domains. The definition of mathematics provided in the New Revised National Curriculum Statement for Grades R-9 in South Africa (Department of Education, 2002: 1) broadens the scope of mathematics far beyond this. The definition states that:

Mathematics is a human activity that involves observing, representing and investigating patterns and quantitative relationships in physical and social phenomena and between mathematical objects themselves. Through this process, new mathematical ideas and insights are developed. Mathematics uses its own specialised language that involves symbols and notations for describing numerical, geometric and graphical relationships. Mathematical ideas and concepts build on one another to create a coherent structure. Mathematics is a product of investigation by different cultures - a purposeful activity in the context of social, political and economic goals and constraints.

The document also outlines the interrelated knowledge and skills included in the scope of mathematics, and stresses the importance of mathematical literacy to enable persons to 
"contribute to and participate with confidence in society" (Department of Education, 2002: 2).

The teaching and learning of mathematics can enable the learner to:

- develop an awareness of the diverse historical, cultural and social practices of mathematics;

- recognise that mathematics is a creative part of human activity;

- develop deep conceptual understandings in order to make sense of mathematics; and

- acquire the specific knowledge and skills necessary for:

- the application of mathematics to physical, social and mathematical problems,

- the study of related subject matter (e.g. other Learning Areas), and

- further study in mathematics" (Department of Education, 2002: 4).

In this context, Daniels and Anghileri (1995) identify the fundamental aim of teaching mathematics as, to equip learners with the strategies, skills, knowledge and most importantly the confidence to use their mathematics to solve problems that learners will encounter throughout their lives. If mathematics teaching does not result in providing learners with these skills, then an important part of their preparation for life is missing and they have been denied access to a basic human right (DoE, 2002).

Also, Denvir et al. (1982) categorise mathematical aims under three broad headings, that is:

Useful: as a tool for the individual and society, e.g. social competence, vocational skills.

Cultural: as part of our culture of which all pupils should have knowledge and experience.

Pleasurable: as a potential source of enjoyment.

They add that the aims for low attainers do not differ from those stated above, although the priorities may differ depending on the needs of the learner. If the experiences in the classroom are not resulting in the learner gaining in any of these categories above, there remains little justification for keeping learners in the mathematics classroom. With the pending implementation of Mathematical Literacy in South Africa (DoE, 2002), which will result in all learners needing to pursue this subject until they leave school, we need to confirm that we do indeed have sufficient justification for keeping all learners learning mathematics. We need to ensure that even the low attainers will profit from the scope and aims of mathematics as outlined above.

Although I acknowledge that in practice computation has been interpreted as a prerequisite to any other mathematical knowledge (Parmar \& Cawley, 1991), by continually focusing too much on this domain, are we allowing low attaining learners the full benefit of the definition and scope of mathematics? Daniels and Anghileri (1995: 23) suggest the following in response to this rhetorical question:

To bring SEN pupils to an understanding of the relationships and patterns that constitute mathematics itself, they will need to be involved with practical tasks, applying mathematics to "real-life" problems, exploring and investigating their findings and discussing their thinking with peers and teachers.

The rest of this article suggests ways in which we can address this, but first examines possible characteristics and causes of low attainment in mathematics.

\section{Possible characteristics and causes of low attainment}

Kroesbergen and Van Luit (2003) draw on the work of Goldman (1989), Mercer (1997) and Rivera (1997), and offer some general characteristics of learners who have difficulty in learning mathematics. These include: memory deficits, inadequate use of strategies for solving mathematics tasks, and deficits in generalisation and transfer of learned knowledge to new and unknown tasks. In this regard Haylock (1991) adds the following to this list: reading and language problems, perceptual problems and poor spatial discrimination, social problems and mathematics anxiety. This is not to say that all low attainers exhibit most or even many of the characteristics outlined above, but that these are general observations from research within this field.

In their book entitled, Low Attainers in Mathematics 5 - 16: Policies and Practices in Schools, Denvir et al. (1982) offer the following list as likely causes of low attainment: physical, physiological or sensory defects; emotional or behavioural problems; impaired performances due to physical causes such as tiredness, drugs and general health; attitude, anxiety, lack of motivation; inappropriate teaching; too many changes of teachers (lack of continuity); general 


\section{The theory of Realistic Mathematics Education as a theoretical framework for teaching low attainers in mathematics}

slowness in grasping ideas; cultural differences, English not first language; impoverished home background; difficulty in oral expression or in written work; poor reading ability; gaps in education, absence from school, frequent transfers from one school to another; immaturity, late development, youngest in the grade; low selfconcept leading to a lack of confidence (Denvir et al., 1982: 19).

They further subdivide these factors into three categories, which include: factors beyond the control of the school, factors partly within the school's control and factors that are directly within the control of the school. The causes, which they then identify as controlled by the school, include:

- inappropriate teaching methods or content;

- lack of suitable materials;

- lack of responsiveness to learner's problems or lack of teacher's time to reflect on the learner's difficulties and plan suitable work;

- a teacher's lack of detailed knowledge of the mathematics being taught, including a knowledge of which skills, concepts, etc are involved;

- a teacher's inability to motivate and involve learners and organise work efficiently. (Denvir et al., 1982: 21)

Also, Feuerstein (1980) has suggested that many different reasons, ranging from genetic to environmental factors, explain low cognitive performance. Abel (1983) takes the standpoint that environment rather than innate ability may be a key factor in learners' performance in mathematics. Referring to research reported by Ginsberg, Klein and Starkey (1998) and Gouws (1992) as examples, Reusser (2000) proposes that there is convincing evidence that most observed failures and low performances in mathematics are due to insufficient teaching-learning environments and not due to genetic factors at all. He also states that learning difficulties that have a neuropsychological diagnosis are "substantially reinforced and shaped by environmental influences such as insufficient measures taken by the instructional and educational support systems" (Reusser, 2000: 1). Baroody and Hume (1991) agree and make a case that most children who experience learning difficulties are recipients of instruction not suited to how children think and learn. This in turn puts the onus on the curriculum and instructional techniques (the environment) as opposed to the learner.
In my opinion, these possible characteristics and causes identified in the preceding paragraphs, suggest that low performance or attainment in mathematics is something that can be "treated". In most cases, it is not an incurable condition that learners are born with, but something that develops as a result of the type of instruction learners receive and the teaching-learning environment (Reusser, 2000) within which they experience mathematics. The implications of this for the inquiry I carried out were: that the instructional approach and teaching-learning environment to be applied in the intervention became central to the literature review and the subsequent choice of a theoretical framework.

\section{Improving teaching and learning mathematics for low attaining learners}

I therefore agree with Abel (1983), Baroody and Hume (1991) and Reusser (2000) and work on the assumption that the environmental aspects of the mathematics teaching and learning can affect a learner's performance. In order to identify the environmental aspects that might make a difference, literature by experts in the field of mathematics education and more specifically low attainment in mathematics was further reviewed. This was done to ascertain whether or not there were any common aspects that could be recognised within the literature. Aspects suggested by various experts are foregrounded (using italics) in the paragraphs below and the common aspects that emerge are summarised in the final paragraph of this sub-section.

In their book entitled Secondary Mathematics and Special Educational Needs, Daniels and Anghileri (1995) examine the benefits of environmental aspects such as appropriate practical work, problem solving, games in the mathematics classroom, group work, co-operative learning, reciprocal teaching and the active participation of learners during lessons. They also stress the point that learning needs to be relevant to the lives of the low attaining learners in order for it to be meaningful. This does not however mean that all mathematics problems should be based in real-life contexts, as puzzles, games, patterns and brainteasers can also be used.

I here want to refer to specific aspects that are relevant for creating conducive learning environments; for instance, Denvir et al. (1982) encourage teachers to embrace the role of experimenters and to try out ideas developed by themselves and their colleagues. In doing so, they 
encourage teachers to observe the low attainers in order to gain some insight into their "strengths and weaknesses, present state of knowledge, and to probable causes of the low attainment..." (1982: 50). This allows the teacher to plan suitable work for individuals that can be extended, adjusted or abandoned, depending on how effective it turns out to be. They in turn warn against continued emphasis on computations (arithmetic skills) at secondary school and motivate this with the indication from research that learners in the 12 to 15 age range show little improvement in their performance in this regard (Hart, 1981). Denvir et al. (1982) also propagate the value of learners discussing their work as well as the advantages of engaging in problem solving with low attainers. Due to the poor memory for facts and procedures that many low attainers appear to have, the research discourages the use of instrumental instruction that relies heavily on memory, and instead encourages more emphasis on relational understanding. In doing so, they refer to the work of Skemp $(1971 ; 1989)$ relating to understanding.

Skemp (1971; 1989) differentiates between relational and instrumental understanding. On the one hand, he suggests that instrumental understanding is "rules without reasons" in that learners may possess the necessary rules, and ability to use them, without actually comprehending why or how that rule works. Often learners will need to memorise more and more of these rules in order to avoid errors and this type of understanding therefore encompasses a "multiplicity of rules rather than fewer principles of more general application" (1989: 5). Relational understanding, on the other hand, involves integrating new ideas into existing schemata and understanding both "what to do and why". Although lower ability learners may need more substantial support than other able learners in constructing their own meanings and connections, this building up of a schema (or conceptual structure) becomes an intrinsically satisfying goal in itself and the result is, once learnt, more lasting. Skemp (1989) uses an analogy of a stranger in a town to differentiate between the two types of understanding. One could have a limited number of fixed plans that take one from particular starting locations to particular goal locations in the town. $\mathrm{He}$ provides this as an example of instrumental understanding. On the other hand one could have a mental map (schema) of the town, from which one can produce, when needed, an almost infinite number of plans to guide one from a starting point to a finishing point, provided only that both can be imagined on the mental map (relational understanding).

The work of Haylock (1991) is significant because it discusses factors associated with low attainers, drawing on classroom-based research, and proposes a strategy for teaching learners in this regard. Although focused on learners who are between 8 and 12 years old, Haylock's book on Teaching Mathematics to Low Attainers can still be considered relevant for lower secondary learners (aged between 13 and 15). Haylock's work foregrounds the following main themes:

- the development of understanding as opposed to the learning of routines and procedures,

- the importance of tending to language development in teaching mathematics,

- the need to specify realistic and relevant objectives for the learners,

- the aspect of numeracy and the basic ability to use a calculator effectively,

- the use of small group games and finally,

- the need to identify "purposeful activities in meaningful contexts" (1991: 5).

Haylock is of the opinion that it is necessary to maintain a balance between providing learners with success through the attainment of set objectives while also providing them with activities in meaningful contexts that they find relevant and purposeful.

Baroody and Hume (1991) suggest that in order for mathematics instruction for low attainers to improve, it needs to focus on understanding, encourage active and purposeful learning, foster informal knowledge, link formal instruction to informal knowledge, encourage reflection and discussion and include Socratic teaching (which involves a combination of the aforementioned elements).

Parmar and Cawley (1991: 1) challenge the "routines and passivity that characterise arithmetic instruction for children with mild handicaps". They suggest that more approaches, which encourage learners to be active, productive learners and allow them the opportunity to demonstrate the extent of their thinking and creativity, are needed in special education classes.

Looking through the aspects above that pertain to the teaching of low attainers mentioned in this sub-section, one that appears repeatedly is the aspect relating to a greater involvement on the part of the learner in the learning process (i.e. the learner being more active). It is suggested more 


\section{The theory of Realistic Mathematics Education as a theoretical framework for teaching low attainers in mathematics}

than once that in order to do this, learners need to be engaged in more meaningful or purposeful contexts, such as problem solving and games. Other aspects referred to by more than one scholarly source are: the need to focus on the development of understanding and the importance of discussions, both between learners themselves and with the teacher.

Using these common aspects from the literature, and drawing on my own experience as a mathematics educator, a list of five aspects to include in the instructional approach to use in the intervention, was compiled. The following section outlines and examines these aspects in more detail.

\section{Relevant environmental aspects in an instructional approach for low attaining learners}

In the previous section, the process that was used to identify the aspects explained in this section was illustrated. A clear demarcation between these aspects is however not intended, as they do overlap on a number of features. The five identified aspects to be focused on in the instructional approach of the intervention are:

- More focus on relational and conceptual understanding as opposed to learning by rote and memorisation (instrumental understanding)

- Creating meaningful learning contexts that actively involve learners

- Greater emphasis on problem solving and less emphasis on computation and arithmetic skills

- The importance of social interaction in the learning process (i.e. group work, reciprocal teaching, games, etc.)

- The importance of language development and discussion with and between learners in teaching mathematics.

\section{More focus on understanding}

As demonstrated by Skemp's (1971) differentiation between relational and instructional understanding, a chasm may exist between what learners are able to do and what they in fact understand. Knowing what to do in a specific situation, but not necessarily understanding why it works, may limit the transfer of that procedure or skill. The increasing number of procedures that learners need to commit to memory in mathematics often results in learners in secondary school becoming confused or partly remembering and trying to apply procedures they have never fully understood (Daniels \& Anghileri, 1995). Understanding on the other hand promotes remembering and enhances transfer owing to the reduced number of bits of knowledge that need to be simultaneously held in the short-term memory (Hiebert \& Carpenter, 1992). The understanding that comes from making connections, seeing how things fit together, relating mathematics to real situations and articulating patterns and relationships also carries with it a satisfaction which can further motivate low attaining learners (Haylock, 1991). Also relating to this point are the fundamental misconceptions that learners might have and the necessity to reveal these in the learning process in order to facilitate further understanding (Hart, 1981; Daniels \& Anghileri, 1995). Adapting to a teaching and learning style that encourages understanding therefore also requires the study of learner errors that occur while solving mathematical tasks (Reusser, 2000). This observation and analysis of errors provides a powerful means for analysing learner understanding as well as being a valuable source of information when used as diagnostic tools (Booth, 1984; Resnick et al., 1989). Rather than being seen as indicators of failure, errors should be viewed as "learning opportunities and as challenges to clarify conceptual misconceptions" (Reusser, 2000: 21).

\section{Involving the learner through the use of meaningful contexts}

It is a common understanding that most people are less resistant to learning something new when they can see the purpose or meaning of it. This is equally important for children at school, especially with regard to mathematics. Many people in fact currently hold an instrumentalist view of mathematics, which Ernest (1988) proposes:

...is the view that mathematics, like a

bag of tools, is made up of an

accumulation of facts, rules and skills to

be used by the trained artisan skilfully in

the pursuance of some external end.

Thus, mathematics is a set of unrelated

utilitarian rules and facts. (1988: 10)

In order to not restrict low attaining learners to this view but to instead meet the challenge of giving learners a full experience of what mathematics is, as defined by the Revised National Curriculum, we need to seriously consider the purposefulness of activities that we require learners to engage in. 
When committed to a task that makes sense to them, there is a good chance that low attainers will surprise us with what they can achieve in mathematics (Haylock, 1991). For this purpose, the teacher should take on the roll of learning facilitator and assist in piquing the curiosity of the learners in order to actively engage them in the task. Active involvement can be regarded as any situation that creates questions or cognitive conflict in children's minds and that further encourages them to rethink their views (Baroody \& Hume, 1991).

Denvir et al. (1982) suggest that low attainers may learn incidentally when they become involved in an absorbing activity and actively participate in the "struggle". They also add that through this activity children may learn because they spot inconsistencies in their thinking, which they then try to resolve. De Korte (1995) lists learning as being "situated" as one of the major features of effective learning processes in mathematics. By this, he means that "learning essentially occurs in interaction with social and cultural context and artefacts, and especially through participation in cultural activities and practices" (1995: 41).

\section{Greater emphasis on problem solving}

As already mentioned, many mathematics interventions currently focus on improving computation skills of low attaining learners. From a number of observations made during school visits, Denvir et al. (1982) concluded that some of the children who do not master arithmetic skills at primary school spend most of their secondary school repeating this computation with very little success. Compounding this is the fact that problem solving is often seen as an activity that is considered unsuitable for low attainers as, amongst other reasons, there are so many other skills to be practised that no time is left for such a luxury (and here clearly views differ on what is regarded as luxury and necessity)! Another reason cited for this is that the basic mathematical knowledge of low attainers is so weak that they will not be able to apply it to the solution of problems. This raises the question as to the usefulness and purpose of this basic mathematical knowledge if it cannot be used when required to solve a problem! As noted by the Cockcroft Report (1982: para. 249):

Mathematics is only 'useful' to the extent to which it can be applied to a particular situation, and it is the ability to apply mathematics to a variety of situations to which we give the name 'problem solving'.
Some of the benefits of the problem solving approach for low attaining learners as identified by Trickett and Sulke (1988) include "better ability and willingness to question, to transfer and apply their mathematics, and to sort out even quite difficult problems" (as cited by Daniels \& Anghileri, 1995: 66).

However, the understanding and solving of even simple mathematical word problems is a complex process that requires skilful interaction of at least three kinds of knowledge: linguistic, situational and mathematical (Reusser, 2000). Learners who are therefore severely lacking in the relevant types of knowledge and skills may instead adopt coping strategies that bypass the logic of mathematical sense-making activities. Such learners in turn need the guidance of "effective pedagogical settings" (2000: 23). This includes presenting problems in contexts that are more familiar, realistic and therefore also meaningful to the learner, while also providing the necessary instruction and strategies to help low attainers to analyse, reflect and practice the overall required sequences in understanding and solving different types of problems.

\section{Social interaction as part of learning}

Cobb and Bauersfeld (1995) identify two general theoretical positions on the relationship between social process and psychological development. While one favours the social and cultural processes (collectivism), the other gives priority to the individual autonomous learner (individualism). One of the most well known theories relating to collectivism is that of Vygotsky (1979 as cited in Cobb \& Bauersfeld, 1995) where "mathematical learning is viewed primarily as a process of acculturation" (1995: 3). Individualism on the other hand is exemplified by neo-Piagetian theories, where the focus is on the individual, autonomous learner as he or she takes part in social interactions. While there appears to be an apparent opposition between these two views, both social and cognitive processes have their place in the learning of mathematics. Cobb and Bauerfeld (1995: 7) cite the following quotation from Saxe and Bermudez (1992):

An understanding of mathematical environments that emerge in children's everyday activities requires the coordination of two analytic perspectives. The first is a constructivist treatment of children's mathematics; Children's mathematical environments cannot be understood apart from children's own 


\section{The theory of Realistic Mathematics Education as a theoretical framework for teaching low attainers in mathematics}

cognizing activities...The second perspective derives from socio-cultural treatments of cognition....Children's construction of mathematical goals and sub-goals is interwoven with the socially organised activities in which they are participants. (1992: 2-3)

Without getting further into these theories, it suffices to say that social interaction remains an integral part of learning. Interactions with both peers and teachers can enhance learning through creating opportunities for learners to share understandings and verbalise thought processes (Daniels \& Anghileri, 1995). Some suggested forms of this are group work, reciprocal teaching, sharing of strategies and games.

Schoenfield (1985) supports the use of small group work for the following reasons: opportunities for teacher assessment, an opportunity for learners to practice collaboration, less secure learners can watch more capable peers struggle, and decision making in a group facilitates the articulation of reasoning and knowledge.

Palinscar and Brown (1988) share an additional instructional procedure for small groups that they refer to as "reciprocal teaching". This mode of cooperative learning assumes the form of a discussion between the members of the instructional group and the teacher (or another facilitator which could also be a learner) who acts as a leader and a respondent. Four strategies are used to direct the discussion. The leader first frames a question to which the group members respond. A piece is then read and the leader summarises the gist of that piece. The group then comments and elaborates on the leader's summary and any necessary points are clarified. Finally, the leader prepares to move onto the next portion of text by making predictions about the upcoming content. Reciprocal teaching is underpinned by the premise that expert-led social interactions can provide a major impetus to cognitive growth (following along the lines of Vygotsky). It therefore plays an important role in learning and has been used by Palinscar and Brown (1988) as a strategy for collaborative problem solving.

Dockrell and McShane (1992) differentiate between learners being able to use a strategy and knowing when to use it. They hold the view that children are often unaware of the effectiveness of a strategy in relation to a particular problem and therefore do not make adequate use of it. However, when learners are encouraged to share their strategies and receive feedback that indicates the positive effect of the strategy, they tend to increase their use of it. The authors also argue that there is a dynamic relation between a knowledge base and strategies. They suggest that:

Strategies often play a vital role in establishing a knowledge base, but once acquired, the role of strategies may become less important within the domain, because the relevant knowledge is available for retrieval. In cases of learning difficulties, it is often the case that the acquisition of knowledge is an issue. Thus, the use of strategies becomes a critical factor. Strategies require a knowledge base that provides the appropriate information on which the strategy can operate. In considering strategy training it is important to consider, as a first step, whether or not the child's knowledge base contains the information required for successful execution of the strategy. (Dockrell \& McShane, 1992: 188)

In the extensive meta-analysis of interventions for students with learning disabilities carried out by Swanson et al. (1999), they classify studies within the analysis into two general approaches, namely direct instruction and strategy instruction. Strategy instruction includes verbal interaction between the teacher and the learners and the learner is viewed as a collaborator in the learning process. The teacher also provides individual feedback and makes use of verbal modelling and "think-aloud" models to solve a problem. From their first tier of analysis it was concluded that: "strategy instruction produces larger effect sizes than those studies that do not use such procedures" (1999: 220). Sharing of strategies can therefore be included as an important aspect that can contribute to effective learning taking place in the teaching of low attainers.

Games are often regarded as primary school activities or something that can be used to fill up time or as an end of term activity. The United Kingdom in particular has recognised the powerful environments created through a game; so much so that it has recently incorporated games that enable assessment into its National Curriculum Assessment. Some of the benefits of games are that they provide the opportunity for learners to practise and consolidate routine procedures and number skills in a motivating environment that is neither threatening nor monotonous (Daniels \& Anghileri, 1995). They also enable learners to 
develop problem solving strategies and aid in the acquisition and development of concepts. The opportunity is also created for teachers to observe their learners' thinking strategies and to interact with learners on a less formal level (Ernest, 1986; Haylock, 1991; Daniels \& Anghileri, 1995).

\section{The importance of language development and discussion}

The effect of language on the learning of mathematics is a widely researched and debated topic not only internationally but also in South Africa (e.g. Howie, 2002; Setati, 2002). While there is no magic formula or solution as to how this issue should be addressed, specifically with regard to low attainers, it nonetheless remains a pertinent issue when designing programs or interventions for these learners. Poor language skills such as reading, writing and speaking are often associated with low attainment in mathematics and, in addition to that, mathematics has its own set of language patterns, symbols and vocabulary. A major part of developing an understanding of mathematics involves learning to handle these and make connections between symbols and their corresponding terminology and meaning (Haylock, 1991). Daniels and Anghileri (1995) stress that speech and written language are the tools of mathematical dialogue. The development of some aspects of mathematical thought may be constrained through a lack of access to these tools. As Dockrell and McShane (1992) point out, when solving a problem it is crucial that the learner first understands the problem before planning and executing a method for solving it.

Understanding is based on the child's cognitive and linguistic skills; planning a method involves constructing a mathematical representation of the problem; carrying out the plan involves executing the mathematical procedures that have been selected...Difficulties can arise in the comprehension of the problem, the construction of the mathematical model, or in the execution of strategies in solving word problems. However, it seems to be the complexity of the text of the word problem and the availability of a suitable basis for its mathematical representation that are the major determinants of performance (1992: 139).

Both the phrases "complexity of text" and "mathematical representation" in the quotation above relate to use of language, in different senses however. The first relates to the written and spoken language of, for example, English. The second refers to mathematics as a collection of symbols, notation and terminology and how these all connect. Difficulties in either (and in many cases both) of these will indeed affect learners' performance and possible development in mathematics.

It would be useful if interventions aimed at assisting low attainers could therefore include components that can be used to diagnose and address the complexity of mathematics as a language and language as a tool for mathematics. This process can be assisted by the use of discussions in the classroom where learners are encouraged to verbalise their understanding, thoughts, solutions and ideas on the problems and tasks presented to them. This is not a simple task, however. In research carried out by Baxter, Woodward and Olson (2001), it was indicated that whole-class discussions are often dominated by verbal, capable learners, while the low attainers tend to remain passive. When they do in fact respond, their answers are typically simple and at times incomprehensible (Ball, 1993; Chard, 1999, as cited in Baxter et al., 2002). Baxter et al. (2002) report on the results and dilemmas that emerged during a year-long case study they carried out that focused on ways to include these learners in class wide discussions of problem solving. One of the major dichotomies they allude to is that remedial environments that bring together only low achieving learners are not likely to result in rich, learner-centred discussions, while regular education classrooms may not provide the most optimal solution to the problem. They therefore suggest the use of small group work and sharing of strategies (without necessarily identifying the best solution) as possible interventions to alleviate the problem.

This section has presented the five aspects and has examined each of them in more detail. Knowing that these aspects were to be the focus of the instructional approach in the intervention, a theoretical framework was sought that would accommodate all of them. The domain-specific theory of Realistic Mathematics Education (RME) from the Freudenthal Institute in The Netherlands was selected as the most appropriate theory to accomplish this task and the theoretical underpinnings of RME are provided in the section below, followed by an explanation of why RME was selected for working with these low attainers. 


\section{The theory of Realistic Mathematics Education as a theoretical framework for teaching low attainers in mathematics}

\section{The theory of Realistic Mathematics Education (RME)}

Realistic Mathematics Education has its roots in Hans Freudenthal's interpretation of mathematics as a human activity (Freudenthal, 1973; Gravemeijer, 1994). To this end, Freudenthal accentuated the actual activity of doing
1987). For example, in what we would typically refer to as a "word sum", the process of extracting the important information required and using an informal strategy such as trial and error to solve the problem, would be the horizontal mathematising. Translating the problem into mathematical language through using symbols and

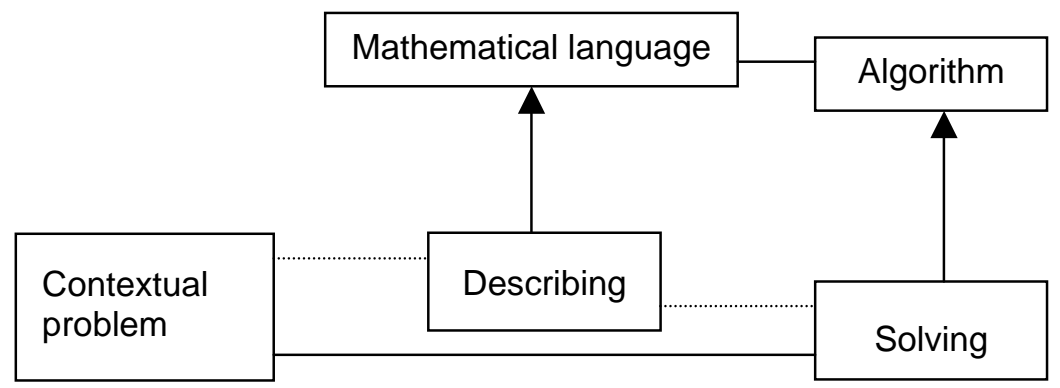

Figure 1 Representation of horizontal and vertical mathematisation Horizontal mathematisation (…….........); Vertical mathematisation $(\longrightarrow)$ Source: Adapted from Gravemeijer, 1994.

mathematics; an activity, which he proposed should predominantly consist of organising or mathematising subject matter taken from reality. Learners should therefore learn mathematics by mathematising subject matter from real contexts and their own mathematical activity rather than from the traditional view of presenting mathematics to them as a ready-made system with general applicability (Gravemeijer, 1994). These real situations can include contextual problems or mathematically authentic contexts for learners where they experience the problem presented as relevant and real.

The verb mathematising or the noun thereof mathematisation implies activities in which one engages for the purposes of generality, certainty, exactness and brevity (Gravemeijer, Cobb, Bowers \& Whiteneack, as cited in Rasmussen \& King, 2000). Through a process of progressive mathematisation, learners are given the opportunity to reinvent mathematical insights, knowledge and procedures. In doing so learners go through stages referred to in RME as horizontal and then vertical mathematisation (see Figure 1). Horizontal mathematisation is when learners use their informal strategies to describe and solve a contextual problem and vertical mathematisation occurs when the learners' informal strategies lead them to solve the problem using mathematical language or to find a suitable algorithm (Treffers, later progressing to selecting an algorithm such as an equation could be considered vertical mathematisation, as it involves working with the problem on different levels.

The traditional formal and authoritarian approach to teaching mathematics that has dominated in South African classrooms for a number of years has not afforded learners many opportunities to make use of horizontal mathematisation. Mathematics lessons are often presented in such a way that the learners are introduced to the mathematical language relevant to a particular section of work and then shown a few examples of using the correct algorithms to solve problems pertaining to the topic before being given an exercise or worksheet to complete (Venter, Barnes, Howie \& Jansen van Vuuren 2004). The exercises or worksheets are usually intended to allow learners to put the algorithms they have been taught into practice and may even contain some contextual problems that require the use of these algorithms. According to the RME model depicted in Figure 1, this type of approach places learners immediately in the more formal vertical mathematisation process. The danger in this is that when learners have entered that process without first having gone through a process of horizontal mathematisation, a strong possibility exists that if they forget the algorithms they were taught, they do not have a strategy in place to assist 
them in solving the problem. As pointed out in the literature in the previous section, this is especially prevalent with low attainers. This experience can be equated to someone being shown and told what is on the other side of a river and being expected to use what is there for their own benefit. However, they are not given or shown the bridge that assists one in crossing to the other side in order to make proper use of what is there. The horizontal mathematisation process provides this bridge.

This section began with an overview of the theoretical underpinnings of RME. The two subsections below endeavour to expand on this synopsis by briefly introducing two important tenets of the theory of RME, namely: the role of developmental research in continually developing and refining the theory, and the instructional design principles that the theory encompasses.

\section{Developing Realistic Mathematics Education}

The RME theory is one that is constantly "under construction", being developed and refined in an ongoing cycle of designing, experimenting, analysing and reflecting (Gravemeijer, 1994). Developmental research plays a central role in this process and, in contrast to traditional instructional design models, focuses on the teaching-learning have invented for themselves. The lesson is implemented and the actual process of learning that takes place in relation to the anticipated trajectory is analysed. This analysis can then provide valuable information in order to revise the instructional activities.

\section{RME instructional design principles}

Gravemeijer (1994, 1999) identifies three key heuristic principles of RME for this process of instructional design, namely:

- Guided reinvention through progressive mathematisation

- Didactical phenomenology

- Self developed or emergent models

\section{Guided reinvention through progressive mathematisation}

The principle of guided reinvention requires that well-chosen contextual problems be presented to learners that offer them opportunities to develop informal, highly context-specific solution strategies (Doorman, 2001). These informal solution procedures may then function as foothold inventions for formalisation and generalisation, a process referred to as "progressive mathematising" (Gravemeijer, 1994). The reinvention process is set

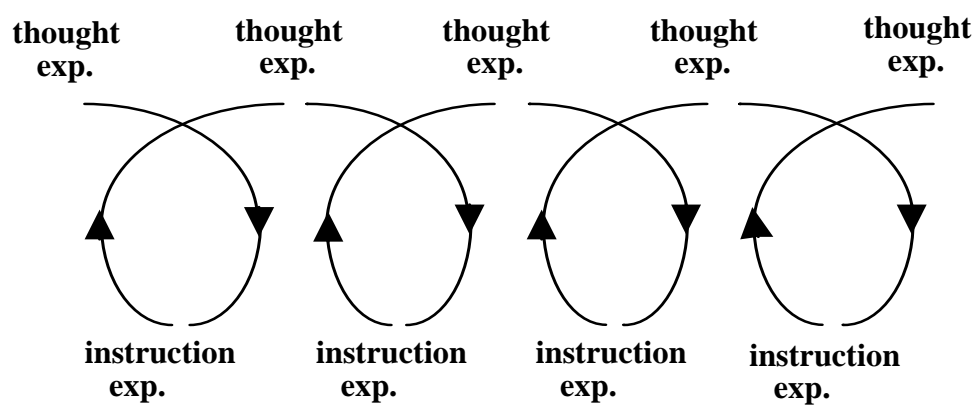

Figure 2. Developmental research, a cumulative cyclic process (Gravemeijer \& Cobb, 2002).

process, focusing in specifically on the mental processes of learners (Rasmussen \& King, 2000). Cyclic processes of thought experiments and instructional experiments form the crux of the method of developmental research and serve a dual function (see Figure 2). They both clarify researchers' learning about learners' thinking and address the pragmatic affairs of revising instructional sequences (Gravemeijer, 1999). Instructional sequences are designed by the curriculum developer who starts off with a thought experiment that imagines a route learners could in motion when learners use their everyday language (informal description) to structure contextual problems into informal or more formal mathematical forms (Armanto, 2002). The instructional designer therefore tries to compile a set of problems that can lead to a series of processes that together result in the reinvention of the intended mathematics (Doorman, 2001).

The idea is not that learners are expected to reinvent everything on their own but that Freudenthal's concept of "guided reinvention" should apply (Freudenthal, 1973). This should in 


\section{The theory of Realistic Mathematics Education as a theoretical framework for teaching low attainers in mathematics}

turn allow learners to regard the knowledge they acquire as knowledge for which they have been responsible and which belongs to them. With guidance, the learners are afforded the opportunity to construct their own mathematical knowledge store on this basis. The word "realistic" in the RME theory does not indicate however that everyday contexts need to be continuously sought or used to motivate learners to reinvent the mathematics. Rather, the contexts selected for use in the process of instructional design should be experientially real for learners, relevant and challenging in order to act as a catalyst for progressive mathematisation (Freudenthal, 1973; Gravemeijer, 1994; Treffers, 1987).

\section{The principle of Didactical Phenomenology}

This principle was advocated by Freudenthal (1973) and implies that in learning mathematics, one has to start from phenomena meaningful to the learner, and that implore some sort of organising be done and that stimulate learning processes.

According to Treffers and Goffree (1985) this principle should fulfill four functions:

- Concept formation (to allow learners natural and motivating access to mathematics),

- Model formation (to supply a firm basis for learning the formal operations, procedures, and rules in conjunction to other models as the support for thinking),

- Applicability (to utilise reality as a source and domain of applications),

- Practice (to exercise the specific abilities of learners in applied situations).

\section{The principle of emergent or self developed models}

This third principle for instructional design in RME plays an important role in bridging the gap between informal and formal knowledge (Gravemeijer, 1994). In order to realise this principle, learners need to be given opportunities to use and develop their own models when solving problems. The term "model" is understood here in a dynamic, holistic sense and learners enhance their models by using their former models and their knowledge about mathematics. As a consequence, the symbolisations that comprise the model and those rooted in the process of modelling can change over time. Learners therefore progress from what is termed a "model-of" a situated activity to a "model-for" more sophisticated reasoning (Gravemeijer \& Doorman, 1999 as cited in Kwon, 2002).

This is quite different from the former (and in many instances still current) practice in South Africa, where learners are presented with a model or algorithm by the teacher and then given repeated opportunities and problems to practise using that model.

\section{Why RME for low attainers}

In the preceding sections in this article, literature on the teaching and learning of mathematics to low attaining learners was examined and common environmental aspects that could be incorporated into the instructional approach of an intervention were identified. The theory of Realistic Mathematics Education was then proposed as a possible theory to drive the design and implementation of such an intervention. The theoretical underpinnings of RME were subsequently outlined. This section expands on these underpinnings and the identified aspects in order to substantiate the choice of RME. To facilitate this argument, RME is discussed in relation to three other global trends in mathematics education in order to highlight some of the unique features, which make it the recommended theory for working with low attainers.

\section{RME in relation to other global innovations in mathematics education}

Treffers (1987) identifies three global trends in mathematics education, which he refers to as the arithmetical, structural and empirical trends. The didactical approach of the arithmetical trend (also known as "New Math") is similar to that of drill and practice instruction in the past with the main objectives being the teaching of certain arithmetic routines, notations and rules and the transfer of knowledge. The influence of the arithmetical trend on RME includes, amongst others, the inclusion of puzzles, practice games and ideas about learning basic operations.

The mathematical activity in the structural trend is mainly directed towards the construction of formal mathematical structures and aims less at the relationships with the reality of everyday experience. The approach is best expressed by the work of Dienes and makes use of "imagined" reality and "artificial surroundings" as a basis for mathematical analysis and exploration of mathematical structures. Treffers (1987) presents the shortcoming of this approach as being the large 
gap between the constructed world in which the mathematics takes place and everyday reality. This makes it almost impossible to connect the two. In spite of this criticism, influences from the structural trend are visible in the work of RME, for example, in the use of arrows and "machines" in the basic operations, in the approach to problems of reasoning via arrow diagrams and the attention paid to structuring aids such as number lines, charts, grids, diagrams and graphics.

In contrast to the structural trend, the empirical trend takes it subjects for mathematics study almost exclusively from the biological, physical or social reality, which means that the starting point for mathematical activities lies within "the neighbourhood of the child's everyday experience" (Treffers, 1987: 10). The lack of a mathematical source of inspiration and strict methodological structure sometimes results in a badly organised collection of activities though, and it becomes problematic to ensure that children are not repeating the same experience at different stages of their school life (Biggs, 1971 as cited in Treffers, 1987). Some similarities between RME and the empirical trend include the use of charts, graphs and materials, the connection with actuality and the attention paid to the measuring aspect of number in early mathematics education. One of the main differences between the two, however, is that while RME draws on everyday contexts, the use of "imagined" realities is also subscribed to, which is not the case in the empirical approach.

The main purpose for presenting this background has been to indicate how elements of global trends, such as these, have influenced the development of the theory of RME. As previously mentioned though, the main thrust of RME is that of viewing mathematics as a human activity (Freudenthal, 1973) and the subsequent central element of mathematisation (Treffers, 1987). This central element of RME is now further investigated and discussed in relation to the other three global trends.

Table 1. Classification by Treffers of inclusion of horizontal and vertical mathematisation in four different mathematics education trends.

\section{Mathematisation for low attainers}

Treffers (1987: 247) describes mathematising as "...the organising and structuring activity in which acquired knowledge and abilities are called upon in order to discover still unknown regularities, connections, structures." Furthermore, mathematising is directed towards:

the acquisition of factual knowledge, the learning of concepts, the attainment of skills and the use of language and other organising skills in solving problems that are, or are not, placed in a mathematical context. (1987: 52-53)

This process or activity alone already accommodates most of the aspects suggested for inclusion in the instructional approach of the intervention for low attainers. To place the instructional approach within one of the other three trends would not allow all five of the suggested aspects to be included. To take this a step further, let us look more closely at the differentiation Treffers (1987) makes between horizontal and vertical mathematisation, as referred to previously. In his words,

In general one can say that 'horizontal mathematisation' consists of a schematisation of the area that makes it possible to attack the problem by mathematical means. The activities that follow and that are related to the mathematical process, the solution of the problem, the generalisation of the solution and the further formalisation, can be described as 'vertical mathematistion'. (1987: 71)

Treffers admits that an exact distinction is hard to make but that the distinction is meaningful in that it demonstrates how activities such as constructing, experimenting and classifying also fit into the process of mathematising along with the more common ones of symbolising, generalising and formalising. Making a schematic comparison between the other three trends and RME, in relation to the use of horizontal and vertical mathematisation, is also a helpful way of

\begin{tabular}{|c|c|c|}
\hline Trends & \multicolumn{2}{|c|}{ Mathematising } \\
\hline & Horizontal & Vertical \\
\hline Mechanistic (Arithmetic) & - & - \\
\hline Empiricist & + & - \\
\hline Structuralist & - & + \\
\hline Realistic & + & + \\
\hline
\end{tabular}




\section{The theory of Realistic Mathematics Education as a theoretical framework for teaching low attainers in mathematics}

demonstrating why RME is being suggested as the domain-specific theory for use with low attainers. In this regard, Treffers (1987) presents the above classification in Table 1.

In the mechanistic (or arithmetic) trend, no real phenomenon is used as a source of mathematical activity, little attention is paid to applications and the emphasis is on rote learning. This results in weaknesses in both horizontal and vertical mathematisation. The empiricist trend places a strong emphasis on horizontal mathematisation in that the emphasis is on environmental rather than on mental operations. Formal mathematical goals do not feature as a high priority and there is little pressure for learners to pass to a higher level, thus demonstrating the weakness with relation to vertical mathematisation. In structuralist instruction, where mathematical structures are emphasised, the vertical component is dominant. This is evident in this approach in that the principal part of the mathematical activity operates within the mathematical system. Instead of real phenomena, embodiments and materialisations of mathematical concepts or structures or structural games are used to create a concrete basis for learners from which to work and real phenomena subsequently do not function as models to support operating within the mathematical system. In realistic mathematics instruction, however, careful attention is paid to both components. As Treffers (1987) puts it,

This means that the phenomena from which the mathematical concepts and structures arise are implicitly used both as source and domain of application. This, according to the tenet of the theory, creates for the learner the possibility of concept attainment by orienting himself to a variety of phenomena, which benefits the building of formal mathematical concepts and structures and their application (1987: 251).

From the literature reviewed in relation to low attainers, it appears that a lot of the teaching and learning in this domain has tended towards the mechanistic (arithmetic) and structuralist trends. The focus of the instruction and assessment has therefore been in the vertical component of Table 1, which could explain the dominance of instrumental rather than relational understanding. The major activities in this component are symbolising, formalising and generalising. As low attainers often struggle with these, they may have experienced repeated failure with continued emphasis on this component. Misconceptions may also be hampering them within the vertical component and may have developed due to a lack of adequate exposure to constructing, experimenting and classifying, which lie in the horizontal component. In order to rectify this, it therefore seems necessary to select an instruction theory that will pay careful attention to both components. Learners are thereby also afforded more opportunities to bridge the gap between their informal understanding and formal knowledge. This is not a once-off or linear process, however, and should be viewed as a continual cycle. The desired outcome is that learners acquire the cyclical strategy of moving between horizontal and vertical mathematisation in order to assist them in improving their understanding and subsequently their performance in mathematics.

From the discussion above, it should be clear that RME provides more of a focus on relational and conceptual understanding as opposed to rote learning. In order to do this, meaningful learning contexts are created (which can be from everyday situations or "imagined" reality) that facilitate the process of progressive mathematisation. This means that learners are actively involved in solving problems and constructing their own meaning and understanding. By continual use of horizontal and vertical mathematisation, learners are using mathematical symbols and language interchangeably and hence tending to the importance of language development. One of the general principles of progressive mathematisation, that has not yet been mentioned, is that of "interactivity" (Treffers, 1987). According to this principle, learners are confronted with the constructions and productions of their peers, which:

...can stimulate them to shorten their learning path, to help themselves up on procedures of others, to become aware of the drawbacks or advantages of their own productions, and that copying others' work slavishly will not aid their own progress. In brief, the learning process is part of the interactive instruction where individual work is combined with consulting fellow students, group discussion, collective work reviews, presentation of one's own productions, evaluation of various constructions on various levels and explanation by the teacher. (Treffers, 1987: 249) 
This principle satisfies the importance of social interaction, an aspect that was earlier identified as being relevant. The central theme of RME, mathematising, therefore adequately incorporates all the aspects suggested for inclusion in an instructional approach for low attainers.

\section{Conclusion}

In this article, the choice of the term "low attainer" was explained and related terminology mentioned. Primary sources of literature in this domain were identified and consulted in order to present some general characteristics and causes of low attainment. These sources were also examined for common environmental aspects and practices to be included in the suggested instructional approach of an intervention for low attaining learners. These aspects were listed and explained. The theory of Realistic Mathematics Education (RME) was then suggested as the theoretical framework to drive the design and implementation of such an intervention. The instructional approach suggested for low attainers is therefore embedded in this domainspecific theory of RME. The theoretical underpinnings of RME were then discussed and RME was examined as an instructional approach to teaching mathematics in relation to three other global trends in this domain. Through this comparison, it was shown how RME is able to satisfy all the aspects suggested in the instructional approach for low attainers. It is therefore recommended that the theory of RME be considered in the design and implementation of interventions with low attainers.

\section{References}

ABEL, T. M., 1983, "Women and mathematics: research vs achievement in education", paper presented at the 9th Annual Midyear Conference of the American Educational Research Association (AERA), Tempe

ARMANTO, D., 2002, Teaching multiplication and division realistically in Indonesian primary schools: A prototype of local instruction theory, unpublished doctoral dissertation: University of Twente, The Netherlands

BAROODY, A.J. \& HUME, J., 1991, "Meaningful mathematics instruction: The case of fractions", Remedial and Special Education 12(3), pp 5468

BAXTER, J., WOODWARD, J. \& OLSEN, D., 2001, "Effects of reform-based mathematics instruction on low achievers in five third-grade classrooms", The Elementary School Journal
101(5), pp 529-549. Retrieved January 23, 2004 from URL: http://gateway.proquest.com

BAXTER, J., WOODWARD, J., VOORHIES, J. \& WONG, J., 2002, "We talk about it but do they get it?" Learning Disabilities Research \& Practice 17(3), pp 173-185

BOOTH, L., 1984, Algebra: Children's strategies and errors. Windsor: NFER-Nelson

CAWLEY, J.F. \& PARMAR, R.S., 1992, "Arithmetic programming for students with disabilities: an alternative", Remedial and Special Education 13(3), pp 6-18

COBB, P. \& STEFFE, L.P., 1983, "The constructivist researcher as teacher and model builder", Journal for Research in Mathematics Education 14, pp 83-94

COBB, P. \& BAUERSFELD, H., 1995, The emergence of mathematical meaning, New Jersey: Erlbaum

COCKCROFT, W., 1982, Mathematics counts: Report on the Committee of Inquiry into the Teaching of Mathematics, London: HMSO

COX, L.S., 1975, "Diagnosing and remediating systematic errors in addition and subtraction computation", Arithmetic Teacher 22, pp 151157

DANIELS, H. \& ANGHILERI, J., 1995, Secondary mathematics and special educational needs, London: Cassell

DE KORTE, E., 1995, "Fostering cognitive growth: a perspective from research on mathematics learning and instruction", Educational Psychologist, 30(1), pp 37-46

DENVIR, B., STOLZ, C. \& BROWN, M., 1982, Low attainers in mathematics 5-16: policies and practices in school, London: Methuen Educational

DEPARTMENT OF EDUCATION, 2002, Annual Report. Retrieved March 21, 2003 from URL: http://education.pwv.gov.za/Policies\%20and\%2 OReports/2002_Reports

DOCKRELL, J., \& McSHANE, J., 1992, Children's learning difficulties: A cognitive approach, Oxford: Blackwell

DOORMAN, M., 2001, "How to guide students? A reinvention course on modelling movement", paper presented at The Netherlands and Taiwan conference on common sense in mathematics education, Taipei, Taiwan. Retrieved April 22, 2003 from URL: http://www.fi.ruu.nl/en/ publications.shtml

DUNLAP, W.P. \& THOMPSON, C.S., 2001, "Diagnosing difficulties in learning basic math fact", Journal of Learning Disabilities 10(9), pp 56-60 


\section{The theory of Realistic Mathematics Education as a theoretical framework for teaching low attainers in mathematics}

ERNEST, P., 1986, "Social and political values", Mathematics Teaching 116, pp 16-18

ERNEST, P., 1988, "The impact of beliefs on the teaching of mathematics", paper prepared for ICME VI, Budapest, Hungary

FAUZAN, A., 2002, Applying Realistic Mathematics Education (RME) in Teaching Geometry in Indonesian Primary Schools, unpublished doctoral dissertation: University of Twente, The Netherlands

FEUERSTEIN, R., 1980, Instrumental Enrichment: An intervention program for cognitive modifiability, Illinois: Scott, Foresman and Company

FREUDENTHAL, H., 1973, Mathematics as an educational task, Dordrecht: Reidel

FREUDENTHAL, H., 1983, Didactical phenomenology of mathematical structures, Dordrecht: Reidel

FREUDENTHAL, H., 1991, Revisiting mathematics education. Dordrecht: Kluwer Academic

GEARY, D.C. \& HOARD, M.K., 2001, "Numerical and arithmetical deficits in learning-disabled children: relation to dyscalculia and dyslexia", Aphasiology 15(7), pp 635-647. Retrieved January 31, 2004 from URL: http://www.tandf.co.uk/journals/pp/0268 7038.html

GRAVEMEIJER， K. \& COBB， P., 2002, "Designing classroom-learning environments that support mathematical learning", presented at the American Educational Research Association conference, April 2001

GRAVEMEIJER, K.P.E., 1994, Developing Realistic Mathematics Education, Utrecht: Freudenthal Institute

GRAVEMEIJER, K.P.E., 1998, "Developmental research as a research method" in Sierpinska, A. \& Kilpatrick, J., eds., Mathematics education as a research domain: a search for identity, pp 277-295. Dordrecht: Kluwer

GRAVEMEIJER, K.P.E., 2001, "Developmental research: fostering a dialectic relation between theory and practice", in Anghileri, J., ed., Principles and practice in arithmetic teaching, London: Open University Press

GRAVEMEIJER, K.P.E., 1999, “How emergent models may foster the constitution of formal mathematics", Mathematical Thinking and Learning, 1(2), pp 155-177

HART, K., 1981, Children's understanding of mathematics, Oxford: Murray
HAYLOCK, D., 1991, Teaching mathematics to low attainers, London: Paul Chapman

HIEBERT, J., \& CARPENTER, T.P., 1992, "Learning and teaching with understanding" in Gouws, D., ed., Handbook for research on mathematics teaching and learning, pp. 65-97. New York: MacMillan

HOWIE, S.J., 2001, Mathematics and Science Performance in Grade 8 in South Africa 1998/1999: TIMSS-R 1999 South Africa, Pretoria: HSRC report

HOWIE, S.J., 2002, English Language Proficiency and Contextual Factors Influencing Mathematics Achievement of Secondary School Pupils in South Africa, unpublished doctoral dissertation: University of Twente, The Netherlands

HOWIE, S.J., BARNES, H., CRONJE, J., HERMAN, C., MAPILE, S. \& HATTINGH, A., 2003, Country profile of South Africa on Science, Mathematics and ICT (SMICT) Education, Pretoria: Centre for Evaluation and Assessment

KILPATRICK, J., 1980, "The development of mathematical abilities in children", in Proceedings of the Fourth International Congress on Mathematical Education (ICME), pp 489-491

KROESBERGEN, E.H. \& VAN LUIT, J.E.H., 2003, "Mathematics interventions for children with special educational needs", Remedial and Special Education 24(2), pp 97-114

KWON, O., 2002, "Conceptualizing the Realistic Mathematics Education approach in the teaching and learning of ordinary differential equations", paper presented at the 2nd International Conference on the Teaching of Mathematics, Greece. Retrieved June 5, 2003 from URL: http://www.math.uoc.gr/ ictm2/ Proceedings/invKwo.pdf

MA, X., 1999, "A meta-analysis of the relationship between anxiety toward mathematics and achievement in mathematics", Journal for Research in Mathematics Education 30(5), pp 520-540

MAGNE, O., 2003, Literature on special educational needs in mathematics: a bibliography with some comments. Retrieved April 28, 2004 from URL: http//www.bit.mah. se/MUEP

MERCER, C. \& MILLER, S., 1992, “Teaching students with learning problems in maths to acquire, understand, and apply basic maths 
facts", Remedial and Special Education 13(3), pp 19-35

PALINSCAR, A.S. \& BROWN, A.L., 1988, "Teaching and practicing thinking skills to promote comprehension in the context of group problem solving", Remedial and Special Education, 9(1), pp 53-59

PARMAR, R.S. \& CAWLEY, J.F., 1991, "Challenging the routines and passivity that characterise arithmetic instruction for children with mild handicaps", Remedial and Special Education 12(5), pp 23-32

RASMUSSEN， C.L. \& KING， K.D., 2000, "Locating starting points in differential equations: A realistic mathematics education approach", International Journal of Mathematical Education in Science and Technology 31, pp 161-173

RESNICK, H., VIEHE, J. \& SEGAL, S., 1982, "Is math anxiety a local phenomenon? A study of prevalence and dimensionality", Journal of Counseling Psychology 29, pp 39-47

RESNICK, L.B. \& FORD, W.W., 1981, The psychology of mathematics for instruction, New Jersey: Erlbaum Associates

RESNICK, L.B., NESHER, P., LEONARD, F., MAGONE, M., OMANSON, S. \& PELED, I., 1989, "Conceptual bases of arithmetic errors: The case of decimal fractions", Journal for Research in Mathematics Education 20(1), pp 8-27

REUSSER, K., 2000, "Success and failure in school mathematics: effects of instruction and school environment", European Child \& Adolescent Psychiatry 9(2), pp 17-26
SCHOENFIELD, A. H., 1985, Mathematical problem solving, Orlando, FL: Academic Press

SETATI, M., 2002, Language practices in multilingual classrooms in South Africa, unpublished doctoral dissertation: University of the Witwatersrand, South Africa

SKEMP, R., 1971, The Psychology of Learning Mathematics, Harmondsworth, UK: Penguin

SKEMP, R., 1989, Mathematics in the Primary School, London: Routledge

SWANSON, H., HOSKYN, M. \& LEE, C., 1999, Interventions for students with learning disabilities: a meta-analysis of treatment outcomes, New York: Guilford Press

TREFFERS, A. \& GOFFREE, F., 1985, "Rational analysis of Realistic Mathematics Education the Wiskobas program", in Proceedings of the Ninth International Conference for the Psychology of Mathematics Education, The Netherlands, II, pp 97-121

TREFFERS, A., 1987, Three Dimensions - A Model of Goal and Theory Description in Mathematics Instruction, Dordrecht: Kluwer Academic

TRICKETT, L. \& SULKE, F., 1988, "Low attainers can do mathematics" in Pimm, D., ed., Mathematics, teachers and children, pp 109117. London: Hodder and Stoughton in association with Open University

VENTER, E., BARNES, H., HOWIE, S.J. \& JANSEN VAN VUUREN, S., 2004, Mpumalanga Secondary Science Initiative Learner Progress Research Project. Pretoria: Centre for Evaluation and Assessment

"Facts do not cease to exist because they are ignored." 